\title{
Erratum to: Caregiver burden in amyotrophic lateral sclerosis: a cross-sectional investigation of predictors
}

\author{
Tom Burke ${ }^{1,2} \cdot$ Marwa Elamin $^{2} \cdot$ Miriam Galvin $^{2,3} \cdot$ Laura Gallagher $^{2}$. \\ Orla Hardiman $^{2,4} \cdot$ Niall Pender ${ }^{1,2,5}$
}

Published online: 14 November 2015

(c) Springer-Verlag Berlin Heidelberg 2015

\section{Erratum to: J Neurol (2015) 262:1526-1532 DOI 10.1007/s00415-015-7746-z}

Unfortunately, one author name was omitted in the original version of the article. The missing author name and affiliation is given below:

Laura Gallagher

Academic Unit of Neurology, Trinity Biomedical Sciences Institute, Dublin, Ireland.

The online version of the original article can be found under doi:10.1007/s00415-015-7746-z.

Tom Burke

burket2@tcd.ie

Marwa Elamin

marwaelamin08@gmail.com

Miriam Galvin

miriam.galvin@dcu.ie

Orla Hardiman

orla@hardiman.net

Niall Pender

niallpender@beaumont.ie

1 Department of Psychology, Beaumont Hospital, Dublin 9, Ireland

2 Academic Unit of Neurology, Trinity Biomedical Sciences Institute, Dublin, Ireland

3 School of Nursing and Human Sciences, Dublin City University, Dublin, Ireland

4 Department of Neurology, Beaumont Hospital, Dublin 9, Ireland

5 Royal College of Surgeons in Ireland, Dublin, Ireland 